\title{
Utilização de extrato hipofisário de galinha Gallus domesticus, para indução a desova de tenca Tinca tinca (L.1758). Opção de banco de hipófise para o pequeno produtor rural ${ }^{\star}$
}

\author{
Utilization of chicken Gallus domesticus, pituitary extracts as tench Tinca tinca \\ (L.1758) spawning agent. A technological option for small farmers
}

Hilton Amaral Júnior**

\begin{abstract}
Resumo
Para não depender de fatores como a temperatura da água, no amadurecimento das gônadas de teleósteos, utilizamse indutores hormonais como a GCH e os extratos hipofisários de carpas (Cyprinus carpio). Ambos produtos apresentam inconvenientes, tanto de resultados técnicos, como de disponibilidade e preço. Pela semelhança de estrutura bioquímica e pela abundância da espécie no estado de Santa Catarina-Brasil, utilizaram-se extratos hipofisários de galinha Gallus domesticus, para induzir a desova de tenca (Tinca tinca). Foram utilizados 63 exemplares de tenca, divididos em quatro lotes. A GCH foi utilizada nos lotes 01 e 04 como indutor de referência. $O$ lote 02 recebeu extrato hipofisário de galinha e o lote 03 não recebeu indução. Os animais foram acondicionados em tanques de alumínio e do tipo DUBISH. Nos resultados avaliaram-se estatisticamente a potencialidade, compatibilidade e efetividade do extrato hipofisário de galinha. Este extrato resultou ser mais efetivo que a GCH para a tenca.
\end{abstract}

Palavras-chave: banco de hipófise; extrato hipofisário; Gallus domesticus, indução artificial; Tinca tinca.

\section{Introdução}

A piscicultura apresenta diferentes níveis de desenvolvimento nos distintos continentes. Enquanto nos países da Europa, Japão, China, EUA, Canadá e outros está muito avançada e a preocupação básica é aumentar o mercado consumidor, em países da América do Sul está pouco desenvolvida.

Muitos fatores prejudicam este desenvolvimento: economia, interesse, capacitação etc. Muitas regiões, como as do sul do Brasil, onde a piscicultura alcança um nível de competição com países mais desenvolvidos, existem problemas que impedem um melhor andamento nos cultivos realizados. Em Santa Catarina, a temperatura da água alcança $18^{\circ} \mathrm{C}$ somente em meados da primavera, inviabiliza muitas vezes algum programa controlado de desova de ciprinídeos. Para resolver este problema e antecipar o amadurecimento de gônadas, é comum utilizar-se indutores hormonais. A administração de extratos hipofisários de carpas é a forma de indução mais utilizada e também uma das mais caras. Existem várias alternativas de indução, cada uma com problemas tanto do ponto de vista de metodologia de aplicação, como estritamente técnicos e de resultados.
Neste trabalho, foi revisada a situação atual das técnicos de reprodução induzida de ciprinídeos, utilizando a tenca (Tinca tinca), uma espécie rústica, pouco conhecida, originária dos países do sul da Europa.

A utilização de extratos hipofisários de galinha Gallus domesticus, abrirá uma linha a mais na área da investigação científica, bem como aumentará as possibilidades já existentes na comercialização de novos produtos, uma vez que há grande produção de aves no estado de Santa Catarina.

Segundo Laegler e colaboradores (1984), existe menor especificidade bioquímica nos hormônios androgênicos e estrogênicos dos peixes, que em mamíferos e aves. Preparações pituitárias inteiras de mamíferos, aves ou répteis, são efetivas em algumas espécies de peixes, para influir no comportamento das glândulas sexuais (Laegler et al. 1984).

A interação entre distintas espécies de animais, é uma prática utilizada a bastante tempo e em muitos países. Para os ciprinideos, é bastante utilizada a interação com aves (galinha, marreco, ganso e pato). As vantagens desta interação residem no aproveitamento racional de uma

\footnotetext{
* Tese Doutoral apresentada na Universidad Complutense de Madrid. 1994. Publicada nos anais do III Encontro Sul-brasileiro de Aquicultura, Ibirubá, RS, 1995 e World Aquaculture (resumos), Seattle USA, 1996. Registrada no Ministério da Cultura sob n. 131.025 livro 206 folha 415.

** Méd.Vet. PhD Pesquisador do CEPC/EPAGRI. Camboriu SC. 88.340.000 - Professor de Aquicultura UNIVALI Itajaí, SC. Prof. Pós-graduação em Aquicultura UFSC, Florianópolis, SC.
} 
mesma área de cultivo e a contaminação ambiental através de utilização racional de resíduos, provocando o favorecimento na multiplicação de zooplancton. Partindo desta interação e observando a possibilidade de aumentar esta linha de trabalho, foi que nos propusemos a utilizar os extratos hipofisários de galinha Gallus domesticus, na indução a desova de tenca Tinca tinca. Consideramos neste trabalho, o simples objetivo de conhecer a compatibilidade, a potencialidade e a eficácia dos extratos hipofisários de galinha na indução a desova de tencas, fazendo uma comparação de dados com a Gonadotropina Coriônica Humana, que atualmente é um dos indutores hormonais mais utilizados em aquicultura.

\section{Material e métodos}

Para o presente trabalho, foram utilizados 63 exemplares de tenca, com dois anos de idade e peso entre 90 e 180 gramas, escolhidas ao acaso de um mesmo tanque de engorda de alevinos, para as fêmeas e um outro tanque de engorda de alevinos para os machos, de iguais características ao primeiro; Gonadotropina Coriônica Humana GCH, marca PHYSEX LEO, em 1.000 e 5.000 UI.; Extrato hipofisário de galinha Gallus domesticus de 63 dias de idade, dissecadas segundo a técnica de Woynarovich, E. (1985), utilizada para a dissecação de hipófises de carpas Cyprinus carpio; Anestésico MS 222 (Aethyliummetaminobenzoicum-methansulfonicum), diluídos na proporção de 1 grama para 12 litros de água; Solução fertilizante (40 gramas de $\mathrm{NaCl}+30$ gramas de $\mathrm{CO}(\mathrm{NH} 2) 2$; Solução antiaderente 85 gramas de $\mathrm{CO}(\mathrm{NH} 2) 2$; Seringas hipodérmicas, agulhas, esponjas, algodão, incubadoras, balança de precisão. Todos os animais foram alimentados durante o tempo dos tratamentos com Daphnia magna, administrada nos tanques 2 vezes ao dia. Todos os tratamentos iniciaram com a temperatura da água acima dos $18^{\circ} \mathrm{C}$. O trabalho foi dividido em quatro tratamentos:

\section{Tratamento I}

No primeiro tratamento, foram utilizados 9 machos e 9 fêmeas de tenca que ao mesmo tempo receberam como indutor hormonal, a Gonadotropina Coriônica Humana. A injeção de indutor sempre foi realizada na parte imediatamente abaixo da nadadeira dorsal. As fêmeas receberam $1 \mathrm{UI}$ por grama de peso vivo, de $\mathrm{GCH}$ repartidas em duas doses de $20 \%$ e $80 \%$ da dose total, em intervalo de 24 horas entre uma e outra dose. Os machos receberam em dose única $100 \%$ da dose total (1 Ul por grama de peso vivo), ao mesmo tempo da última dose das fêmeas. Os animais ficaram durante este primeiro tratamento, em um tanque de alumínio de $300 \times 50 \times 60$ centímetros.

\section{Tratamento /I}

No segundo tratamento foram utilizados 9 machos e 9 fêmeas de tencas. Como indutor utilizamos os extratos hipofisários de galinha. As fêmeas receberam 6 miligra- mas por quilograma de peso vivo de indutor, dissolvidas em 4 mililitros de soro fisiológico, em dose única. Os machos receberam 2 miligramas por quilograma de peso em dose única, ao mesmo tempo da dose das fêmeas. Estes animais ficaram em tanques de alumínio durante o experimento. A desova foi realizada de maneira artificial e os ovos foram incubados em incubadoras do tipo ZOUG.

\section{Tratamento III}

Para este tratamento, utilizamos apenas 9 fêmeas de tenca. Estas fêmeas não receberam nenhum tipo de indução hormonal e ficaram ao mesmo tempo que as demais fêmeas dos outros experimentos em tanques de alumínio, até a comprovação de sua maturidade sexual. A realização deste experimento, foi para comprovar se 0 estresse causado pela mudança dos reprodutores, do meio ambiente ao qual estão acostumados durante 0 período de vitelogênese, interferiu na maturidade sexual final.

\section{Tratamento IV}

No quarto tratamento, foram utilizados 9 machos e 9 fêmeas de tenca, acondicionadas em um tanque de alumínio. Como indutor hormonal, estes animais receberam $\mathrm{GCH}$. As fêmeas receberam $2 \mathrm{UI}$ por grama de peso, sendo que as doses foram de $50 \%$ da dose total em intervalo de 24 horas. Os machos receberam 1 UI por grama de peso em dose única, ao mesmo tempo da segunda dose das fêmeas. Após receberem a última dose, os animais passaram para tanques do tipo DUBISH modificado, onde foi adaptada uma vegetação artificial do tipo RÁFIA. O tipo de desova foi natural e os ovos foram incubados dentro do próprio tanque.

\section{Resultados}

\section{Tratamento I}

No primeiro tratamento, com a utilização da GCH para indução à desova de tencas, obtivemos uma efetividade de $55,56 \%$, já que, das 9 fêmeas tratadas artificialmente, 5 desovaram e 4 não chegaram a desovar. Todos os machos deste lote responderam positivamente à indução. Das fêmeas que responderam positivamente, foram extraídos os produtos gonadais em quase sua totalidade e, para os machos, foi necessária a utilização de canulação, que é a retirada do líquido espermático através de cânula.

\section{Tratamento II}

No segundo experimento, a utilização de extratos hipofisários de galinha resultou ser efetiva em $100 \%$, já que as 9 fêmeas de tencas utilizadas no experimento chegaram a desovar. Os machos responderam positivamente à indução, mas apresentaram pouca quantidade de sêmen. 


\section{Tratamento III}

No terceiro experimento, sem a utilização de indutor hormonal e sem a presença de machos, as fêmeas não chegaram a desovar. Não houve maturação das gônadas, verificada pela falta de desova após 710 dias graus.

\section{Tratamento IV}

No quarto e último tratamento, as fêmeas chegaram à desova no $28^{\circ}$ dia, o que veio a confirmar que no período inicial do experimento, estas não estavam sexualmente maduras e somente conseguiram desovar devido à atuação dos indutores hormonais. Comprovamos também, neste experimento, que o estresse causado pela mudança de meio ambiente, durante o período de vitelogênese em fêmeas reprodutoras de tencas, impede a maturação normal dos óvulos e faz com que ocorra uma atresia folicular, e conseqüente degeneração dos folículos e regressão com absorção dos produtos gonadais.

\section{Discussão}

\section{Indução hormonal com GCH e desova artificial}

No primeiro tratamento realizado, o lote testemunha, no qual as fêmeas tinham as mesmas características e condições, vinham de um mesmo tanque de engorda e a mesma idade, a resposta a indução com a $\mathrm{GCH}$, foi de $55,56 \%$, já que o êxito de indução com $\mathrm{GCH}$ depende muito do grau de maturidade das gônadas dos reprodutores e da temperatứa da água (Harvey e Hoal, 1980).

Em realidade, os resultados de efetividade que apresenta a utilização de $\mathrm{GCH}$ em desovas de tenca, a não ser por sua grande oferta e fácil aplicação, não representa uma alternativa eficaz, já que seu custo é muito alto em comparação com seus resultados. No primeiro experimento, onde apenas 5 fêmeas chegaram a desovar, o peso corporal aparentemente não teve influência, já que houve fêmeas de 123 e 153 gramas que desovaram e outras com 128 e 137 que não chegaram a desovar.

\section{Indução com extratos hipofisários de Gallus domesticus, em desova artificial}

No segundo tratamento, as fêmeas e os machos receberam como indutor hormonal à desova, os extratos hipofisários de galinha. Experimentos demonstraram que nas aves existem também os hormônios gonadotrópicos (FSH e LH) dos mamíferos. O hormônio estimulante dos folículos (FSH) e o hormônio luteinizante (LH) estimulam o crescimento das glândulas sexuais, tanto masculinas como femininas, e a produção de esteróides e gametos (King et al., 1979). Estes experimentos demonstraram que estruturalmente o GnRH dos teleósteos, era similar ao dos elasmobrânquios, répteis e aves e que diferia dos de mamíferos e anfíbios. Entretanto, a atividade biológica de todos eles era parecida.
Segundo Peter et al. (1985), existe menos especificidade bioquímica nos hormônios androgênicos e estrogênicos dos peixes, que nas aves e mamíferos.

Os resultados que conseguimos ao final do segundo experimento, com a utilização de extratos hipofisários de Gallus domesticus, para indução à desova de Tinca tinca, prova a eficácia e a compatibilidade da hipófise de galinha em relação à dos peixes.

Para Carrillo et al. (1987), os hormônios armazenados na hipófise das aves são quimicamente semelhantes aos hormônios dos teleósteos. As seqüências aminoácidas dos hormônios hipotalâmicos são efetivamente muito semeIhantes. A potencialidade dos extratos hipofisários de galinha não deixam margem de dúvidas, já que todo o lote 2 desovou dentro de 48 horas seguintes à indução hormonal.

\section{Reprodutores sem indução hormonal}

O terceiro experimento constatou a imaturidade gonadal que apresentavam as fêmeas, nas datas em que se realizou o experimento. Os 34 dias que passaram nos tanques, com temperatura da água acima dos $18^{\circ} \mathrm{C}$, não foram suficientes para que chegassem à maturação sexual.

As fêmeas experimentaram uma provável atresia folicular com a conseqüente reabsorção gonadal, causadas pelo estresse da mudança de meio ambiente. O fator estresse é o que mais danos causa a uma maturação gonadal em tencas (Pérez Regadera y Pérez, 1993). É evidente a importância que tem o hipotálamo na informação neural dos estímulos externos, através das células neurossecretoras que vão do cérebro até o sistema hormonal. Estas células neurossecretoras, ao receber o sinal do cérebro de que "tudo vai bem", informam ao hipotálamo, que produz os chamados hormônios liberadores. Em contrapartida, existe um fator hipotalâmico que inibe a liberação de gonadotropina hipofisária, que é o GRIF, ao qual estão relacionados todos os fatores que podem impedir a desova de uma fêmea, inclusive a ausência de machos durante o tratamento. Ao comprovarmos esta regressão gonadal ao final do experimento, utilizamos a técnica de Lin et al. (1986) para comprovar o estado imaturo dos óvulos.

\section{Indução com Gonadotropina Coriônica Humana e desova natural}

As tencas do último lote utilizadas no experimento desovaram ao final de 28 dias. $O$ único estímulo artificial que receberam foi a aplicação de $\mathrm{GCH}$, que serviu para antecipar a maturação gonadal. As fêmeas conseguiram desovar também, porque não estavam estressadas como as do terceiro lote, já que o meio ambiente em que ficaram, tanques com vegetação artificial do tipo ráfia, tinha semeIhança com o meio ao qual estavam acostumadas, que possuía vegetação aquática natural. 


\section{Análises estatísticas}

Figura 1: Análise pelo teste de t da influência do peso das fêmeas nas desovas ocorridas no experimento

\begin{tabular}{c|c|c|r}
\hline $\begin{array}{c}\text { Lote de fêmeas } \\
\text { com } \\
\text { desova artificial }\end{array}$ & $\begin{array}{c}\text { Número } \\
\text { de fêmeas }\end{array}$ & $\begin{array}{c}\text { Peso Total } \\
(\mathrm{g})\end{array}$ & $\begin{array}{c}\text { Peso Médio } \\
(\mathrm{g})\end{array}$ \\
\hline 1 & 4 & 478 & 119,5 \\
\hline 2 & 9 & 860 & 95,5 \\
\hline Total 2 & 13 & 1338 & $102,9 \pm 15,3$ \\
\hline
\end{tabular}

\begin{tabular}{c|c|c|c}
\hline $\begin{array}{c}\text { Lotes com } \\
\text { desova }\end{array}$ & $\begin{array}{c}\text { Número de } \\
\text { fêmeas }\end{array}$ & Peso Médio (g) & G.L. \\
\hline 1 & 5 & 145,2 & \\
\hline 2 & 9 & 104,0 & \\
\hline 4 & 9 & 109,1 & \\
\hline Total 3 & 23 & $119,9 \pm 23,1$ & $-1,23$ \\
\hline
\end{tabular}

Como o valor calculado para t, é de -1,23 e o valor encontrado na tabela para $5 \%$ de probabilidade é de 2,04 , considera-se o resultado não-significativo, concluindo-se que o peso das fêmeas não influiu no resultado. Portanto, estatisticamente, os lotes são de uma mesma população.

Conclui-se neste trabalho a necessidade de um estudo em maior profundidade da quantificação e períodos de maior produção dos hormônios LH e FSH da glândula pituitária da galinha, assim como estudos complementares em relação aos outros hormônios produzidos pela mesma. Igual- mente é conveniente estabelecer as implicações no desenvolvimento da maturação das gônadas de peixes e os conseqüentes mecanismos de indução a desova.

$O$ custo dos indutores que foram utilizados neste trabalho (US $\$ 1,75$ por quilograma de reprodutor induzido com $\mathrm{GCH}$ e US $\$ 0,25$ por quilograma de reprodutor induzido com extrato hipofisário de galinha) refletem as vantagens da utilização do soro hipofisário pelas estações que trabaIham com reprodução artificial, levando-se em conta a espécie de peixe utilizada para este trabalho.

\section{Conclusões}

Com a utilização de soro hipofisário de Gallus domesticus, para indução à desova de Tinca tinca, como uma opção de banco de hipófise para o pequeno produtor rural, podese chegar as seguintes conclusões:

1 As fêmeas de tenca com 2 anos de idade não estão sexualmente maduras, sendo impossível um programa de desova com reprodutores desta idade.

20 peso das fêmeas de tenca utilizadas nos experimentos (83 e 158 gramas), não influenciou nos resultados.

3 A administração de $\mathrm{GCH}$ antecipou a maturação das gônadas.

4 A GCH é eficaz na dose de 1 Ul/g para indução à desova (50 a $60 \%)$ de tenca.

5 Os hormônios da hipófise de galinha são mais potentes e eficazes que a GCH na hora de induzir à desova de tenca.

6 A indução hormonal com extratos hipofisários de galinha é economicamente mais viável que a indução com GCH.

\begin{abstract}
Hormonal agents like HCG and fish pituitary glands are commonly used to overpass natural constraints in fish spawning. However, both have drawbacks, i.e., uncertain technical results, availability and high prices. Hen (Gallus domesticus), pituitary glands are physiologically similar to fish glands and highly available in Santa Catarina, Brazil. In the present study we used hen pituitary glands extracts to induced tenca Tinca tinca, to spawn. In total we had 63 fishes in our experiment, divided in 4 batches. HCG was used to induce fishes on batches 1 and 4 as a reference model to fish induction. Fishes of batch 2 received hen pituitary extract and those on batch 3 did not received any induction agent. Fish were kept on aluminum tanks and Dubish ponds. Data obtained were statistically analysed and hen pituitary extract was evaluated in terms of potentiality, compatibility and effectiveness on fish spawning induction. The results showed that hen pituitary extract was more effective and potent than HCG. Hen pituitary extract was also found to be compatible to tinca fish spawning as an induction agent.
\end{abstract}

Keywords: Hypophisis bank; pituitary extracts; Gallus domesticus; artificial spawning induction; Tinca tinca.

\section{Referências bibliográficas}

CARRILLO, M., SANTAELLA, E., ZANUY, S., ARNAL, I. Reproducción y desarrollo larvario de peces. Cuadernos Marisqueros. España. v. 10, p. 63-72, 1987.

HARVEY, B. J. e HOAL, W. S. Teoría y práctica de la reproducción inducida en los peces. Centro Internacional de Investigaciones para el Desarrollo. Otawa. Canadá. 1980. 48 p.
KING, J. A. e MILLAR, R. P. Heterogenity of vertebrate cuteinizing hormone-releasing hormone. Science, v. 206, p. 67-69. 1979.

LAEGLER, K. L., BARDACH, J. E., MILLER, R. R. Ictiologia. Editorial AGT. México.1984. 489 p.

LIN, R. H.; KRAAK G,V, D.; LIANG, J. Y.; PENG, C. The effects of $L H-R H$ analogue and drugs wich black the effects of 
dopamine on gonadotropin secretion and ovulation in fish cultured in China. Aquaculture of cyprinids. Billard, R. (Ed.). INRA, Paris. France. p. 139-150.

PÉREZ REGADERA Y PÉREZ, J. J. La ciprinicultura. Consejería de Agricultura y Pesca. Badajóz, España. 55 p. 1993.

\section{Anexos}

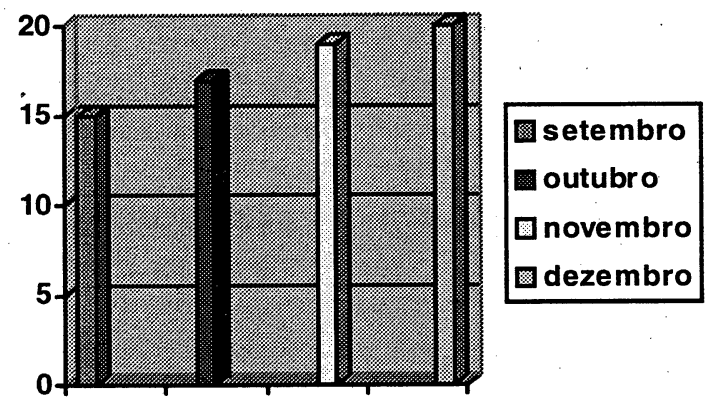

Figura 2: Temperatura média $\left({ }^{\circ} \mathrm{C}\right)$ da água, no estado de Santa Catarina, Brasil.
PETER, R. E., NAHORNIAK, C. S., SOKOLOWSKA, M. Structureactivity relation ships of mammalian chicken and salmos gonadotropin releasing hormone in vivo in goldfish. Gen. Comp. Endocrinol. v. 58, p. 231-242. 1985.

WOYNAROVICH, E. Manual de piscicultura. CODEVASF. Brasil. 45 p. 1985.

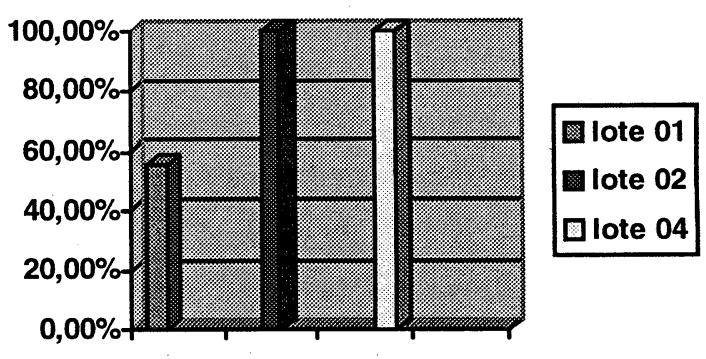

Figura 3: Comparação da efetividade da GCH (tratamentos 1 e 4) e os extratos hipofisarios de galinha (tratamento 2) e o tipo de desova.

\begin{tabular}{|c|c|c|c|c|}
\hline : & $\mathrm{T} 1$ & $\mathrm{~T} 2$ & T 3 & T 4 \\
\hline Animais & $9 \mathrm{M} / 9 \mathrm{~F}$ & $9 \mathrm{M} / 9 \mathrm{~F}$ & $9 \mathrm{~F}$ & $9 \mathrm{M} / 9 \mathrm{~F}$ \\
\hline Indutor & $\mathrm{GCH}$ & Extrato hipofisario & $\therefore$ & $\mathrm{GCH}$ \\
\hline \multirow[t]{2}{*}{ Dose / Quantidade } & M: 1 Ul/g peso & $\mathrm{M}: 2 \mathrm{mg} / \mathrm{Kg}$ peso & 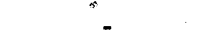 & $1 \mathrm{UI} / \mathrm{g}$ peso \\
\hline & F: 1 UI/g peso & $\mathrm{F}: 6 \mathrm{mg} / \mathrm{Kg}$ peso & & 2 UI/g peso \\
\hline \multirow[t]{2}{*}{ Dose / Forma } & M: dose única & M: dose única & - & M: dose única \\
\hline & $F: 20$ e $80 \%(24 h)$ & F: dose única. & & $F: 50$ e $50 \%(24 h)$ \\
\hline \multirow[t]{2}{*}{ Observar resultados } & Desova artificial & Desova artificial & Sem Desova & Desova Natural \\
\hline & Incubação Artificial & Incubação Artificial & & Incubação Natural \\
\hline Temperatura Média & $20,2 \mathrm{C}$ & $20,3 C$ & $21,3 \mathrm{C}$ & $20,1 \mathrm{C}$ \\
\hline \multirow[t]{2}{*}{ Tanques } & Alumínio & Alumínio & Alumínio & Cimento com ráfia \\
\hline & $300 \times 50 \times 60 \mathrm{~cm}$ & $300 \times 50 \times 60 \mathrm{~cm}$ & $300 \times 50 \times 60 \mathrm{~cm}$ & $400 \times 500 \mathrm{~cm}$ \\
\hline
\end{tabular}

Figura 4: Tabela de características do material e métodos. 